\title{
NZR, Rat Strain
}

National Cancer Institute

\section{Source}

National Cancer Institute. NZR, Rat Strain. NCI Thesaurus. Code C14411.

Tumors (atriocaval epithelial mesotheliomas) of right atrium or inferior vena cava occur in approximately $12-20 \%$ of animals of both sexes over 1 year. These tumors are slow growing, but apparently malignant, and closely resemble similar tumors found in humans (Goodall et al 1975). In a later study, most common neoplasms of animal over one year of age: atrioclaval mesotheliomas 12\%, lung adenomas 10\% (males), pituitary adenomas $23 \%$, mammary tumors 7\%, liver tumors 3\%, cervical tumors 3\% (in females) (Goodall and Doesburg 1981). 